\title{
Upper-mantle velocity structures beneath the Tibetan Plateau and surrounding areas inferred from triplicated $P$ waveforms
}

\author{
RiSheng Chu ${ }^{1 *}$, LuPei Zhu ${ }^{2,3}$, and ZhiFeng Ding ${ }^{4}$ \\ 'State Key Laboratory of Geodesy and Earth's Dynamics, Institute of Geodesy and Geophysics, Wuhan 430077, China; \\ 2Department of Earth and Atmospheric Sciences, Saint Louis University, St Louis, MO 63108, USA; \\ ${ }^{3}$ Institute of Geophysics and Geomatics, China University of Geosciences, Wuhan 430074, China; \\ ${ }^{4}$ Institute of Geophysics, China Earthquake Administration, Beijing 100083, China
}

\begin{abstract}
P-wave waveforms in the distance range between $12^{\circ}$ and $30^{\circ}$ were analyzed to investigate upper-mantle $P$ velocity structures beneath the Tibetan Plateau and surrounding areas. The waveform data from 504 earthquakes with magnitudes larger than 5.0 between 1990 and 2005 that occurred within $30^{\circ}$ from the center of the Plateau were modelled. We divided the study area into 6 regions and modeled upper-mantle-distance $P$ waveforms with turning points beneath each region separately. The results show that the uppermantle P-wave velocity structures beneath India, the Himalayas, and the Lhasa Terrane are similar and contain a high-velocity lid about $250 \mathrm{~km}$ thick. The upper-mantle velocities down to $200 \mathrm{~km}$ beneath the Qiangtang Terrane, the Tarim Basin, and especially the SongpanGarzê Terrane are lower than those in the south. The 410-km discontinuity beneath these two terranes is elevated by about $20 \mathrm{~km}$. Highvelocity anomalies are found in the transition zone below $500 \mathrm{~km}$ under the Lhasa and Qiangtang Terranes. The results suggest that the Tibetan Plateau was generated by thrusting of the Indian mantle lithosphere under the southern part of Tibet. Portions of the thickened Eurasian mantle lithosphere were delaminated; they are now sitting in the transition zone beneath southern Tibet and atop of the 410$\mathrm{km}$ discontinuity underneath northern Tibet.
\end{abstract}

Keywords: Tibetan Plateau; upper mantle structure; triplication; waveform modelling

Citation: Chu, R. S., Zhu, L. P., and Ding, Z. F. (2019). Upper-mantle velocity structures beneath the Tibetan Plateau and surrounding areas inferred from triplicated P waveforms. Earth Planet. Phys., 3(5), 444-458. http://doi.org/10.26464/epp2019045

\section{Introduction}

The Tibetan Plateau, bounded by the Tarim Basin and North China Blocks to the north and the Indian sub-continent to the south, has been created by collision between the Indian plate and the Eurasian plate (Figure 1). The collision started about 70-50 Ma ago (Molnar and Tapponnier, 1975). Since then, the India plate has continued to move northward into the interior of Eurasia. As a result, about $1,000 \mathrm{~km}$ of $\mathrm{N}-\mathrm{S}$ convergence between India and Eurasia has taken place (Yin A and Harrison, 2000; Johnson, 2002). For collisions involving at least one oceanic plate, the convergence is always accommodated by subduction of one or more of the oceanic plates. It is still not clear how large convergence can be accommodated when both plates are continental. Various collision models have been proposed to explain the convergence between the Indian and Eurasian plates and the uplifting of the Tibetan Plateau, including 1) under-thrusting of the Indian plate beneath the Eurasian plate (Argand, 1924), 2) injection of the Indian crustal material into the weak Tibetan lower crust (Zhao WL and Morgan, 1985; Xu Q et al., 2015), 3) distributed shortening and vertical

Correspondence to: R. S. Chu, chur@asch.whigg.ac.cn

Received 25 MAY 2019; Accepted 06 AUG 2019.

Accepted article online 23 AUG 2019.

(C) 2019 by Earth and Planetary Physics. thickening of the Eurasian lithosphere (England and Houseman, $1986)$, 4) subduction of the Indian plate underneath the Eurasian plate in the middle of the Plateau (Owens and Zandt, 1997; Royden et al., 2008), and 5) multiple southward subductions of Eurasian mantle lithosphere underneath Tibet (Fan GW and Wallace, 1991; Tapponnier et al., 2001). Figure 2 shows simplified sketches of these models.

Each of these models predicts a unique crust and upper mantle structure. The under-thrusting model suggests a shield-like mantle lithosphere beneath the Plateau, similar to the one beneath India. The Eurasian mantle lithosphere should be removed to accommodate the advancing of Indian mantle lithosphere (Figure 2a). Injection of the Indian crust into the Tibetan lower crust would require a weak lower crust beneath the Tibetan Plateau (Figure $2 \mathrm{~b}$ ). In the distributed shortening model, in order to raise the northern Plateau to reach an elevation of $5 \mathrm{~km}$, the thickened Tibetan mantle lithosphere has to be removed by a thermal instability or small-scale mantle convection (England and Houseman, 1986) (Figure 2c). Subduction of the Indian plate in the middle of Tibet Plateau would result in a thicker crust in southern Tibet than in northern Tibet and a high-velocity subducting slab beneath the Bangong suture (Figure $2 \mathrm{~d}$ ). Models of intracontinental subductions of both the Indian plate and Eurasian plate beneath the Tibetan Plateau are characterized by multiple slabs in 


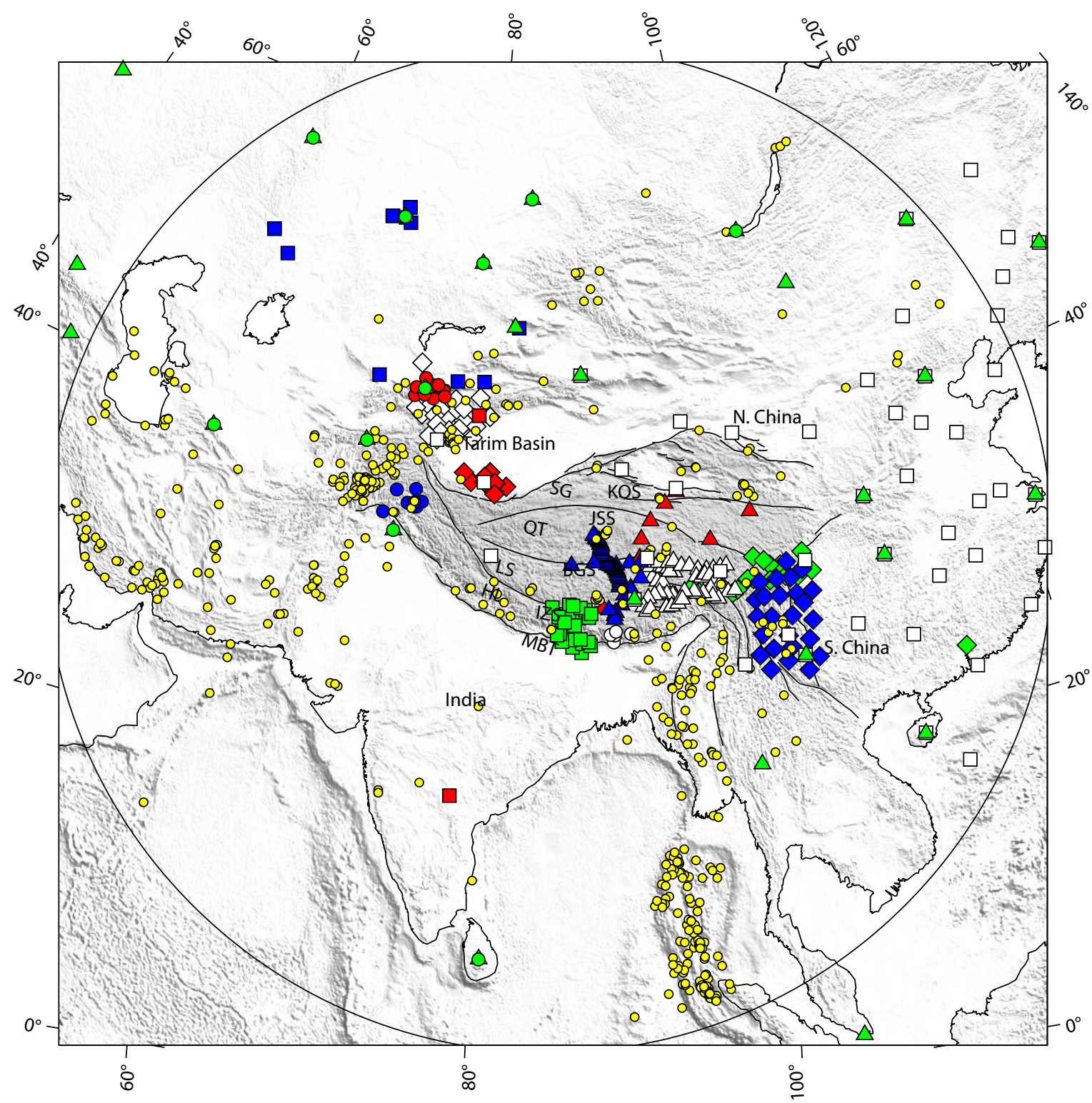

Figure 1. Map of the Tibetan Plateau and surrounding area. Dark grey represents areas of $5 \mathrm{~km}$ above sea level. HL: the Himalayas, LS: the Lhasa Terrane, QT: the Qiangtang Terrane, SG: the Songpan-Garzê Terrane, MBT: the Main Boundary Thrust, IZS: the Indus-Zangbo Suture, BGS: the Bangong Suture, JSS: the Jinsha Suture, KQS: the Kunlun-Qinling Suture. Earthquakes with $M_{\mathrm{w}} \geq 5$ from January 1990 to February 2005 with distances less than $30^{\circ}$ from the center of the Tibetan Plateau are plotted as yellow dots. Other symbols represent permanent and temporary seismic stations around the Tibetan Plateau, including the Chinese National Digital Seismic Network (white squares), the Kirghiz Telemetered Network (red dots), GEOSCOPE stations (red squares), IRIS/IDA network (green dots), the Kazakhstan Network (blue squares), and the Global Seismographic Network stations (green triangles), the 1991-1992 Sino-US PASSCAL experiment (red triangles), the 1994 INDEPTH II and 1997-1999 INDEPTH III experiment (blue triangles), the 1995-1996 Nanga Parbat Pakistan experiment (blue dots), the 1997-2001 Tian Shan Continental Dynamics experiment (white diamonds), the 1998 Southwestern Tarim experiment (red diamonds), the 2001-2002 Himalayan Nepal Tibet Seismic experiment (green squares), the 2002-2003 Bhutan Pilot experiment (white dots), the 2003-2004 Namche Barwa Tibet experiment (white dots), the 2003-2004 MIT-China seismic experiment (blue diamonds), and the 2004-2006 Sichuan Tibet experiment (green diamonds).

the upper mantle beneath Tibet (Figure 2e). Therefore, the upper mantle structure beneath the Plateau is key to discriminating among different models.

A lot of progress has been made to reveal the seismic structures beneath the Tibetan Plateau. Seismological efforts include classical modeling waveforms in the upper-mantle distances (e.g. Zhao WJ et al., 1991; Chen WP and Tseng, 2007; Zhang RQ et al., 2011), surface-wave dispersion analyses (e.g. Yang YJ et al., 2010; Li HY et al., 2014), travel-time tomography (e.g. He RZ et al., 2010; Bao XW et al., 2013, Liang XF et al., 2016), and receiver function analysis (e.g. Wang CY et al., 2010; Zhao JM et al., 2010; Yue H et al., 2012; Pan SZ and Niu FL, 2011; Shen XZ et al., 2014). Most of these studies, however, focus on structures in the crust and uppermost mantle shallower than $100 \mathrm{~km}$ (e.g. Zhu LP et al., 1995; Zhu LP and Helmberger, 1998; Guo XY et al., 2013; Liu QY et al., 2014). Less at- 

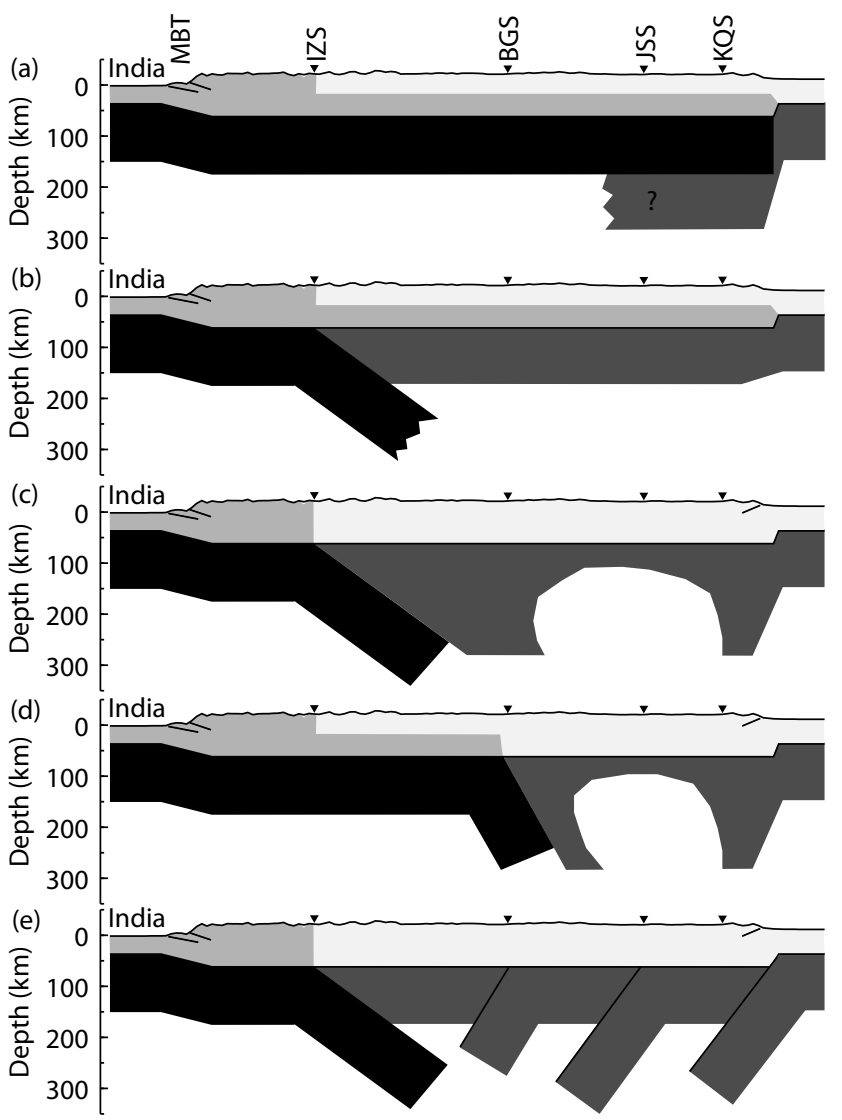

Figure 2. Five India-Eurasia collision models: (a) underthrusting, (b) injection, (c) distributed shortening, (d) subduction of the Indian plate beneath the Bangong Suture, and (e) intra-continental subductions.

tention has been given to deeper regions, which would also be expected to yield good indications of the tectonic history of the Tibetan Plateau. In this study, we used waveforms in the distance range of $12^{\circ}$ and $30^{\circ}$, whose ray paths turn between depths of 100 $\mathrm{km}$ and $850 \mathrm{~km}$, to obtain the upper-mantle velocity structures beneath the Tibetan Plateau and surrounding areas. The waveforms and differential travel times between different phases are very sensitive to upper mantle velocity structure. Such a study is now possible because large amounts of high-quality waveform data have accumulated over the last decade from the increasing number of seismic stations deployed in and around Tibet.

\section{Method}

Because waveforms return both arrival time and shape information from different seismic phases, waveform modeling imposes unique constraints on seismic structures (Chu RS et al., 2012a; Chu RS and Helmberger, 2014). Among these approaches, uppermantle triplications provide a powerful way to determine upper mantle velocity structures, as applied to USArray data of the United States (Chu RS et al., 2014, 2012b, 2013).

As seismic velocities increase with depth, a seismic wave turns at a certain depth before being recorded by a receiver on the surface. If there is a rapid velocity increase or velocity jump, three seismic rays can arrive at the same station: 1 ) a ray turning above the discontinuity, 2) a ray reflected from the discontinuity, and 3) a ray
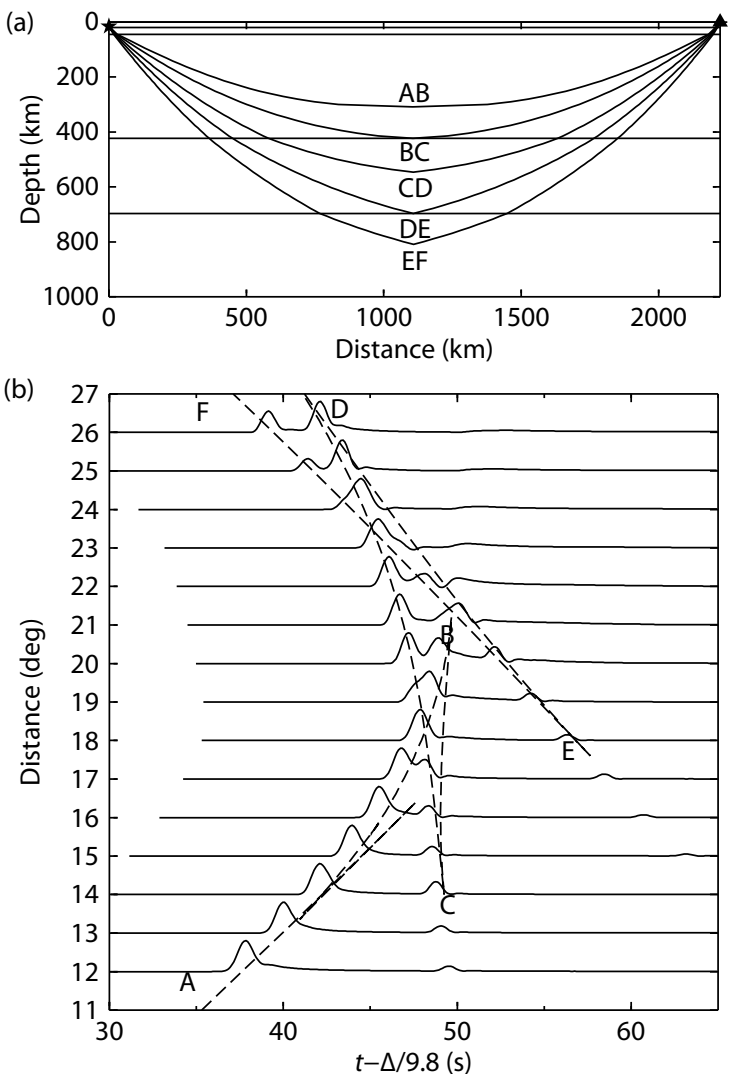

Figure 3. Top panel shows seismic ray paths to a station at a distance of $20^{\circ}$. The bottom panel shows a record section of $P$ waves in the distance range of $12^{\circ}$ and $26^{\circ}$. Black dashed lines represent arrival times of different branches associated with the 410 and 660 discontinuities.

turning below the discontinuity (Figure 3a). Consequently, three phases appear on the seismogram. This phenomenon is often referred as upper-mantle triplication. In the upper mantle, there are two major velocity discontinuities, at depths of about $410 \mathrm{~km}$ and $660 \mathrm{~km}$, both of which are due to mineral phase changes (Bina, 1991). Thus, two sets of triplication exist. For the global IASP91 velocity model and a shallow source, the 410-km discontinuity's triplication appears from $12^{\circ}$ to $21^{\circ}$. The $A B$ and $C D$ branches cross at $18^{\circ}$. The triplication of the $660-\mathrm{km}$ discontinuity begins at about $17^{\circ}$ and ends at $28^{\circ}$. The CD and EF branches meet at around $23^{\circ}$ (Figure 3b).

Upper-mantle triplications provide a unique way to determine upper mantle velocity structure. As shown in Figure 3a, the seismic wave of the $A B$ branch travels nearly horizontally around its turning depth above the 410 discontinuity and is mostly sensitive to the velocity at this depth. The seismic waves of other branches turn in the transition zone and the lower mantle, where velocity structures are relatively more homogeneous laterally. Their arrivals can serve as reference time marks. Because all the rays share similar paths near the source and station, the differential travel times between the $A B$ branch and the deeper branches are less influenced by the earthquake origin-time error and shallow velocity structural variations.

To demonstrate this, we placed a high-velocity anomaly between 
$200 \mathrm{~km}$ and $250 \mathrm{~km}$ in the velocity model used in Figure 3. The Pwave record section and the perturbed velocity model are shown in Figure 4a. It shows that this high-velocity anomaly changes the separations between $A B$ and $B C$ branches only in the distance range of $16^{\circ}$ to $18^{\circ}$, with the largest separation change at about $17^{\circ}$. Waveforms at other distances are almost intact.

Since the differential arrival times between the $A B$ branch and other branches are used, there is a trade-off between the velocity in the shallow upper-mantle and the deep part. For instance, a large separation between the $A B$ and $B C$ branches could also be explained by a low-velocity anomaly just above the 410 discontinuity or by a deeper 410 discontinuity. Figure $4 \mathrm{~b}$ shows this trade-off by two sets of triplicated waveforms. A deeper 410 discontinuity (at $426 \mathrm{~km}$ ) can fit the large separation in waveforms at distances between $16^{\circ}$ and $18^{\circ}$. In this situation, it cannot be decided whether these waveforms are produced by a deeper 410 discontinuity or by high velocities in the top upper-mantle.

To reduce the trade-off in the waveform modeling, we used a "bottom-up" strategy to determine velocity structure in the deep part first by modeling waveforms at large distances, and then moving upward to the shallower depths. The advantage of this modeling technique is that it can reduce the trade-off and eliminate the effect of large velocity uncertainties of the shallow structures, especially the crust. We will use the phase with deep turning depths as the reference phase, on which the synthetic and the observed seismograms are aligned. Velocities near the turning depth of the shallow phase will be adjusted through trial and error to fit both the arrival time and amplitude of the shallow phase.

\section{Data}

In order to study upper-mantle velocity structures beneath Tibet, seismograms at epicentral distances between $10^{\circ}$ and $30^{\circ}$ are needed. To ensure that their turning points are located in the study area, we restricted earthquakes to those with distances less than $30^{\circ}$ from the center of the Tibetan Plateau $\left(85^{\circ} \mathrm{E}, 33^{\circ} \mathrm{N}\right.$, Figure 1). Using the Preliminary Determinations of Earthquakes (PDE) catalog, we found 1,715 earthquakes between January 1990 and February 2005 with magnitudes larger than 5.0. We then verified the Harvard CMT solutions of all events using their teleseismic $P$ waveforms. We found 504 earthquakes with correct focal mechanisms (Figure 1). Earthquake depths and source time functions were re-determined using a method described in Chu RS et al. (2009).

The 504 earthquakes were recorded by some of more than 300 permanent and temporary broadband seismic stations in and around the Tibetan Plateau. Permanent stations include 48 stations from the Chinese National Digital Seismic Network (CNDSN, network code $C D$ ), 13 stations from the Kirghiz Telemetered Network (KNET, KN), 13 stations from the Kazakhstan Network (Kaznet, KZ), and several Global Seismographic Network (GSN) stations (Figure 1). During this time period, many seismic recording experiments were conducted around Tibet, providing additional
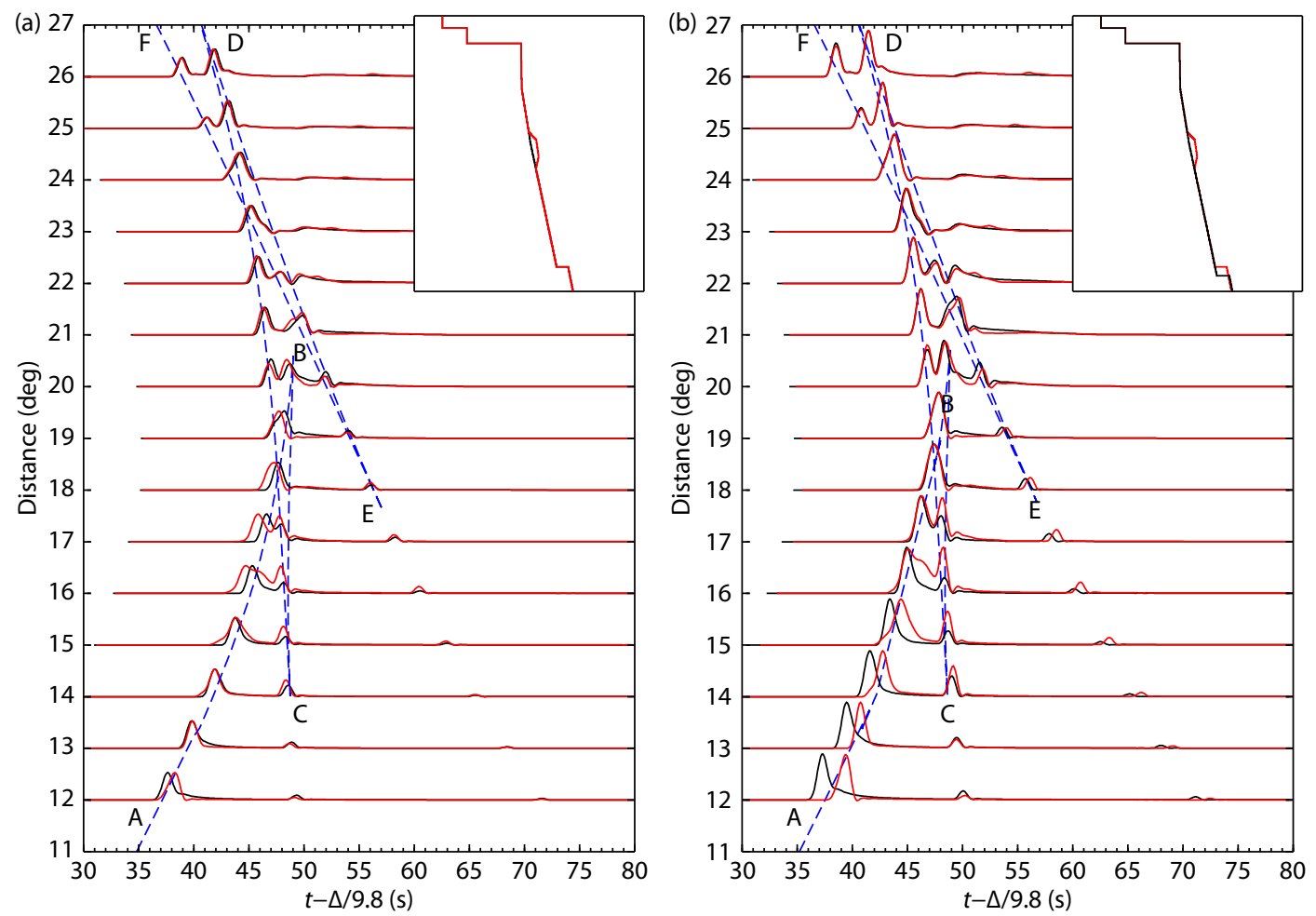

Figure 4. The left panel presents a sensitivity test, using triplicated waveforms, of two different upper-mantle velocity models (shown in the insert box). The waveforms are aligned at the EF branch. The red-color seismograms correspond to the model with a high-velocity anomaly between $200 \mathrm{~km}$ and $250 \mathrm{~km}$. The right panel illustrates the trade-off of modeling (see text). The red-color model and P-wave profile are the same as in the left panel. The black-color profile corresponds to the model without the high-velocity anomaly but with a deeper 410 discontinuity. The synthetics are aligned at the $C D$ branches. 
station coverages in the study area (Figure 1). These temporary stations were deployed during several PASSCAL-type experiments: the 1991-1992 Sino-US PASSCAL experiment (XC) (Owens et al., 1993), the 1994 INDEPTH II and 1997-1999 INDEPTH III experiments (XR) (Zhao WJ et al., 1993; Nelson et al., 1996; Alsdorf et al., 1998; Zhao W et al., 2001), the 1995-1996 Nanga Parbat Pakistan experiment (XG) (Meltzer et al., 2001), the 1997-2001 Tian Shan Continental Dynamics experiment (GHENGIS, XW) (Xu Q et al., 2007), the 1998 Southwestern Tarim experiment (XM) (Kao et al., 2001), the 2001-2002 Himalayan Nepal Tibet Seismic experiment (HIMNT,YL) (De La Torre and Sheehan, 2005), the 2002-2003 Bhutan Pilot experiment (XA) (Velasco et al., 2007), the 2003-2004 Namche Barwa Tibet experiment (XE) (Sol et al., 2007), the 2003-2004 MIT-China seismic experiment (YA) (Yao HJ et al., 2006), and the 2004-2006 Sichuan Tibet experiment (XS) (Wang CY et al., 2010). Temporary stations were mainly deployed in eastern and southern Tibet (Figure 1).

Most waveforms recorded by these broadband stations were acquired from the IRIS Data Management Center. We used a time window of $30 \mathrm{~s}$ before the predicted P-wave arrival time and $60 \mathrm{~s}$ after to retrieve the desired $\mathrm{P}$ waveforms from the raw data. We removed instrument responses from each waveform, re-sampled the trace with a sampling rate of 10 points per second, and bandpass filtered the data between frequencies of $0.02 \mathrm{~Hz}$ and $1.0 \mathrm{~Hz}$. To ensure waveform quality, we visually inspected each waveform and discarded bad traces. In total, we used 11,306 seismograms in the distance range between $10^{\circ}$ and $30^{\circ}$. Their turning points cover most parts of the western Tibetan Plateau, the Hindu-Kush area, and the Hindu-Burma region. Western Tibet, eastern Tibet, and the Tarim Basin have excellent coverage by waveforms with a distance range between $12^{\circ}$ and $20^{\circ}$, corresponding to turning depths between 100 to $400 \mathrm{~km}$, while central Tibet and southern Tibet have less-than-ideal coverage for this distance range (Figure 5).

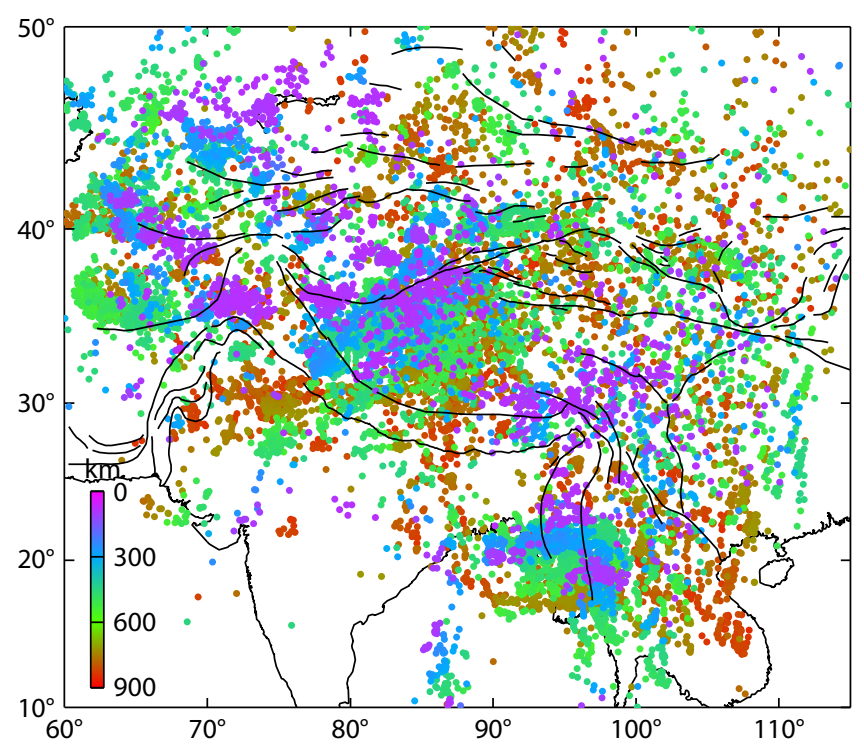

Figure 5. Turning point (color dots) distribution of 11,306 P-wave waveforms from 504 earthquakes.

\section{Results}

\subsection{Travel-Time Residuals}

We first handpicked the first $\mathrm{P}$ arrival times in all waveforms and computed their travel-time residuals with respect to the IASP91 velocity model. In order to remove the arrival time delays caused by inaccurate event origin times and near-source structural heterogeneities, we calculated the source delay for each event by minimizing the root-mean-square of travel-time residuals between observations and predictions by the IASP91 model for the EF branch.

We averaged the travel-time residuals using a bin size of $2.5^{\circ} \times$ $2.5^{\circ} \times 100 \mathrm{~km}$. Figure 6 shows the averaged residuals for traces turning at $800 \mathrm{~km}, 500 \mathrm{~km}, 300 \mathrm{~km}$, and $100 \mathrm{~km}$, respectively. We placed the travel-time residuals at the turning points because the residuals are most sensitive to the velocities near the turning points. Negative travel-time residuals indicate that the velocity around the turning point is faster than the IASP91, and positive residuals suggest slow velocity anomalies. Travel-time residuals below the 400 are small throughout the study area (Figures 6a and $6 \mathrm{~b})$. Their magnitudes are usually smaller than $1.0 \mathrm{~s}$, which indicates that the velocities in the transition zone and lower mantle beneath the whole area are close to the IASP91. In contrast, negative residuals above the 400 dominate most of the area (Figures $6 c$ and $6 \mathrm{~d}$ ), including India, southern Tibet, central Tibet, and eastern Tibet. The difference between the observed arrival times and predictions can be as large as $-7.0 \mathrm{~s}$, which means that the velocities above the 410 are faster than the IASP91 upper-mantle velocities in these areas. Positive travel-time residuals, which suggest lower velocities, are mainly concentrated between $200 \mathrm{~km}$ and $300 \mathrm{~km}$ beneath the southern Tarim Basin, western Tibet, and southeastern Asia (Figure 6).

\subsection{Waveform Modeling}

Based on the major fault and suture systems, we divided the area along the NS direction in Figure 7 into six regions: India, the Himalayas $(\mathrm{HL})$, the Lhasa Terrane (LS), the Qiangtang Terrane (QT), the Songpan-Garzê Terrane (SG), and the Tarim Basin (TB) (Figure 7). Waveforms with turning points beneath each region were grouped for modeling to obtain the best 1-D upper-mantle velocity model for the region. To ensure good data quality, we inspected each waveform in the group and kept only those with a clear first $P$ arrival. We then used the verified Harvard CMT solutions and revised focal depths to compute synthetic seismograms. This helped identify other late phases. Since the modeling technique relied on using a deep-turning phase, such as the $C D$ and $E F$ branches, as the reference phase to align the data and synthetic waveforms, only traces with at least one clear deep-turning phase were used for the modeling.

Waveforms in each group were from different earthquakes at various depths, which made the waveform modeling more difficult. Figure 8 a shows synthetic $P$ waveforms from two events, one at a depth of $30 \mathrm{~km}$ and the other at $10 \mathrm{~km}$. If we align these two profiles at the first arrivals directly, the late phases are misaligned at a given epicentral distance. In order to construct a single epicentral distance waveform profile for modeling, it is necessary to correct 

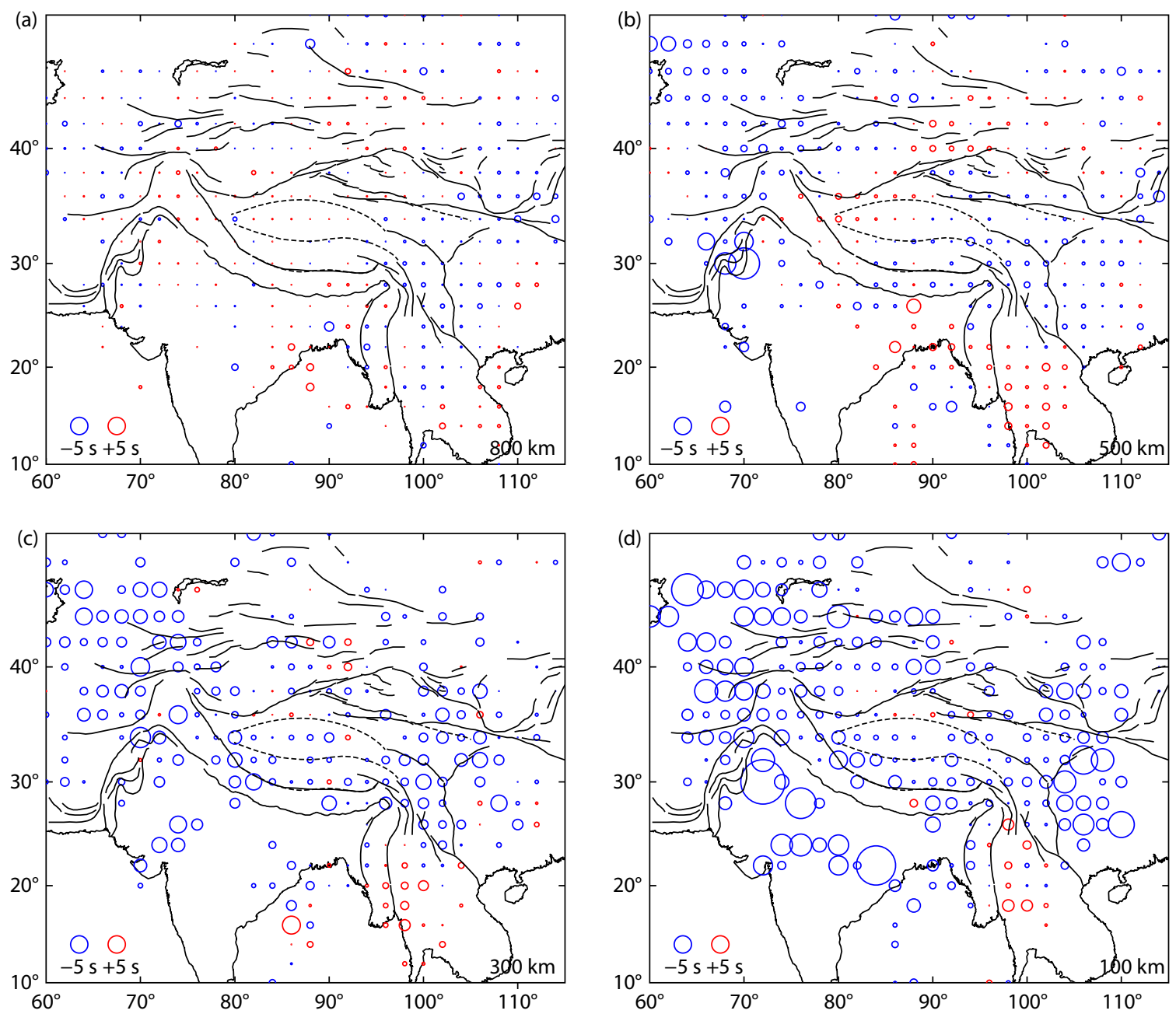

Figure 6. Travel-time residuals for seismic rays turning below the 660 discontinuity (upper left), in the transition zone (upper right), above the 410 discontinuity (lower left), and around $100 \mathrm{~km}$ depth (lower right). Size of the symbol corresponds to magnitude of the residual.

for the source-depth effect because waveforms from a deep earthquake have larger "effective" epicentral distances on the distance profile than those from a shallow event. We chose $10 \mathrm{~km}$ as the reference source depth because most of the events used in this study were shallow earthquakes with focal depths at 4-30 km (Chu RS et al., 2009). Differences between the true and effective epicentral distances were estimated using the ray parameter of the first arrivals and the background velocity model. After correcting for the source-depth effect, all seismograms can be placed on a single epicentral distance profile for modeling (Figure 8b).

\subsubsection{India and the Himalayas}

There were fewer usable traces with turning points beneath India compared to other regions, mainly because there are fewer available stations and less seismicity in the stable continent. Therefore, we treated all of India as one unit. In order to minimize the effect of the upper-mantle structure beneath the collision front, we chose those paths with turning points at least $200 \mathrm{~km}$ away from the MBT. A total of 12 traces with distances ranging from $16^{\circ}$ to $28^{\circ}$ were selected. Figure 7 shows locations of event-station pairs and their turning points used for obtaining velocity structure beneath India.
We first analyzed 4 traces at distances of $22^{\circ}$ to $28^{\circ}$ to constrain the velocity structure between the 660 and 410 discontinuities. Depths of the turning points, which provide a good coverage of the transition zone, are shown in black circles. At this distance range, only $C D$ and EF branches and their depth phases are clear, as indicated by dashed lines (Figure 9a). Since the EF branch turns below the 660 discontinuity, we choose it as our reference phase. The observed data and synthetic seismograms are aligned along the EF branch. Observed CD branch agrees with the IASP91 prediction, and synthetic seismograms from the IASP91 model match the observations well for these four traces (Figure 9a), which suggest that the velocity structure below the 410 is the same as the global average model.

At shorter distances between $16^{\circ}$ and $21^{\circ}$, the EF branches have small amplitudes and are hard to identify. Fortunately, use of $C D$ branches larger than $20^{\circ}$ can resolve the velocities in the transition zone very well (Figure 9b). Therefore, we chose the CD branch as our reference phase to align the 8 remaining waveforms. The separations between the $A B$ and $C D$ branches in the observations are about $5.0 \mathrm{~s}$ larger than the IASP91 predictions (Figure 9a). The early AB branch suggests high-velocity anomalies in the upper mantle above the 410 discontinuity. We estimated 


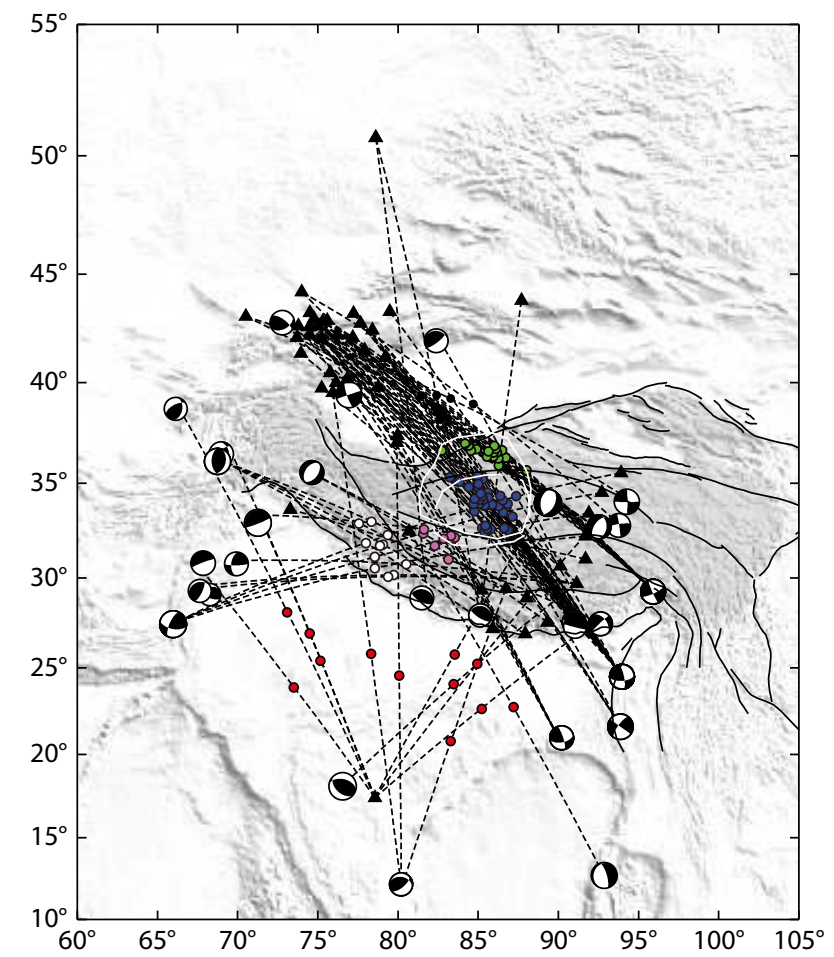

Figure 7. Event-station pairs used to obtain upper-mantle velocity structures in this study. Color dots are turning points sampling each terrain. White dashed line represents the area where high-velocity anomaly was found in the transition zone. White contour indicates the region where elevated 410 discontinuity and low-velocity anomaly between $100 \mathrm{~km}$ and $200 \mathrm{~km}$ depth were seen.

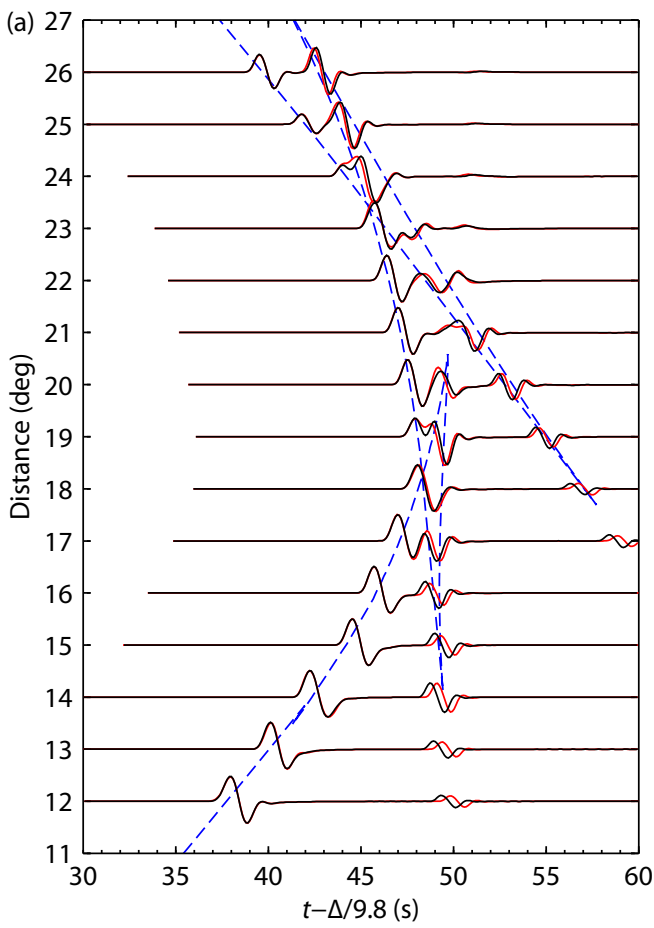

the turning depths of these waveforms using the IASP91 model and adjusted velocities around the turning depths until the synthetics matched the data. Figure 9a shows the final waveform fits. The best-fit velocity model has a thick high-velocity lid to a depth of $250 \mathrm{~km}$ with a P-wave velocity of $8.41 \mathrm{~km} / \mathrm{s}$ (Figure $9 \mathrm{~b}$ ).

For the Himalayas, we show 11 waveforms with distances between $14^{\circ}$ and $26^{\circ}$, whose ray paths sample depths from 100 $\mathrm{km}$ to $660 \mathrm{~km}$ (Figure 9). The same modeling strategy was used to obtain upper mantle velocities. Similar to the structure beneath India, a high-velocity layer is obtained at the depths of $70 \mathrm{~km}$ to $230 \mathrm{~km}$ beneath the Himalayas with waveform fits shown in Figure $9 \mathrm{c}$ and velocities shown in Figure $9 \mathrm{~d}$.

\subsubsection{The Lhasa Terrane}

In Figure 10a we show a profile of 7 seismograms used to constrain the upper-mantle velocity structure beneath the Lhasa Terrane. Three waveforms at distances between $23^{\circ}$ and $26^{\circ}$ sample the lower part of the transition zone (Figure 10b). The observed CD and DE branches are 1.0-1.5 s earlier than the IASP91 predictions and the crossover distance of $C D$ and $E F$ is larger than that of IASP91. Since the CD branch is the $P$ waves turning above the 660 discontinuity and the DE branch consists of $P$ waves reflected from the discontinuity, the observations suggest a highvelocity anomaly in the transition zone. Modeling of the waveforms yields a velocity increase of $2.5 \%$ between $550 \mathrm{~km}$ and 660 $\mathrm{km}$ and the 660 discontinuity is depressed about $15 \mathrm{~km}$, as shown in Figure 10b. We verified the model using $P$ waveforms from another earthquake at this distance range and compared them with synthetic seismograms calculated using IASP91 (Figure 10c) and

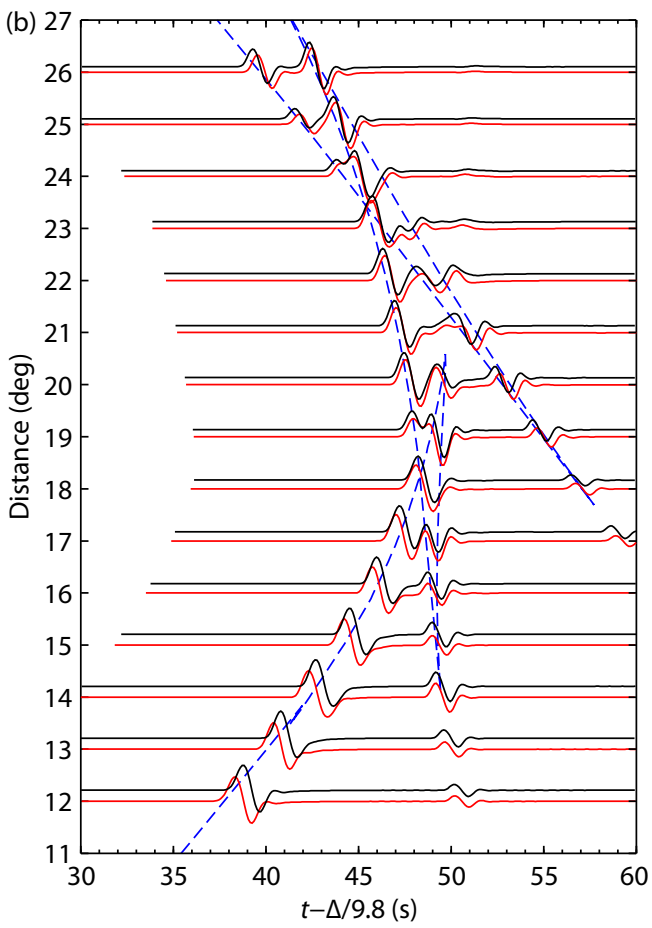

Figure 8. (a) Synthetic $P$ waveforms in the upper-mantle distances from two earthquakes with the focal depths at $30 \mathrm{~km}$ (black) and $10 \mathrm{~km}$ (red). (b) Same as in (a) except that the epicentral distances of the waveforms from the $30 \mathrm{~km}$ deep event (black) have been corrected to the effective epicentral distances of a $10 \mathrm{~km}$ deep source. 

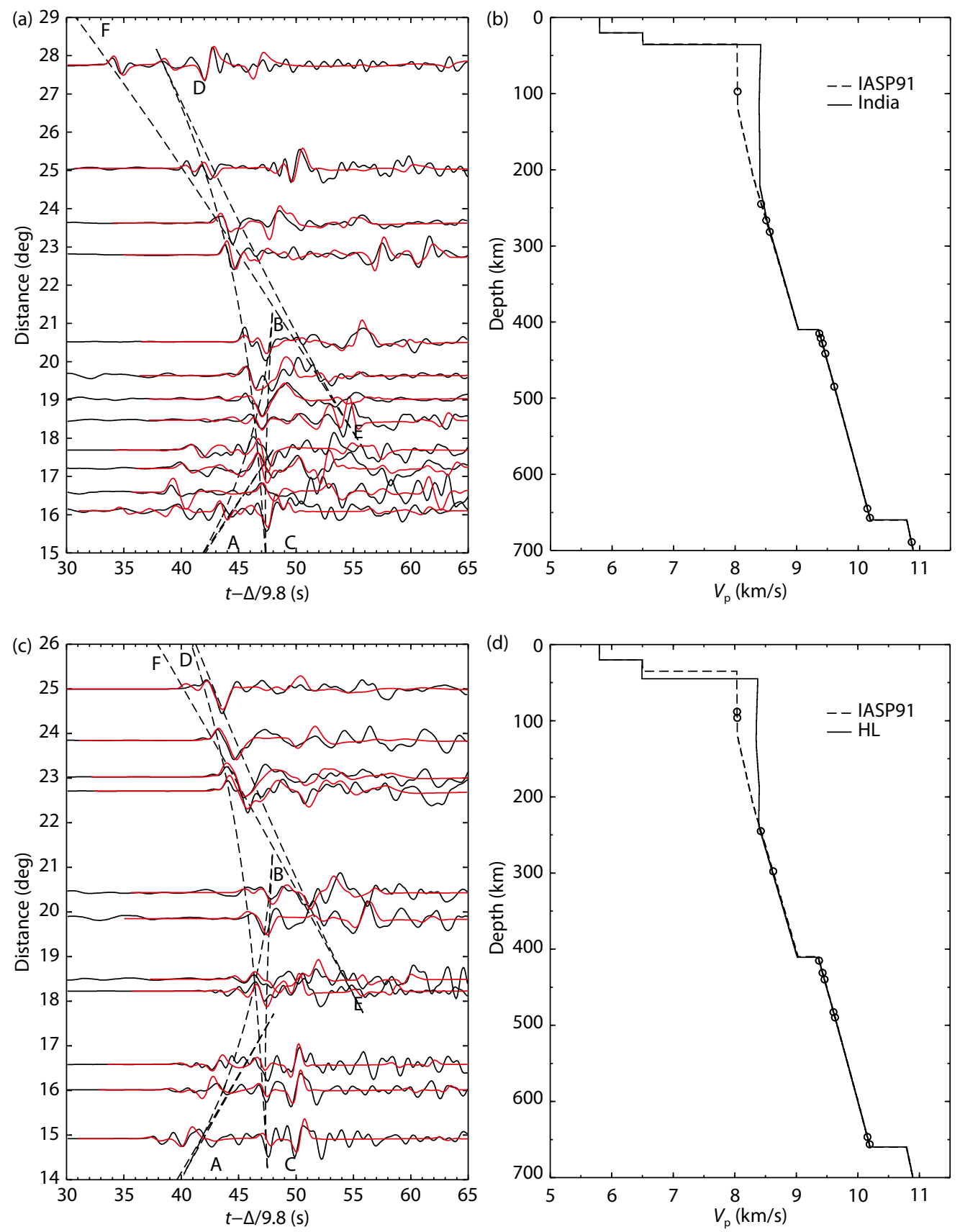

Figure 9. Waveform fits for India (top) and the Himalayas (bottom). Black-colored seismograms are observed data. Red traces are synthetic seismograms of the best 1-D model shown on the right. Black dashed lines represent arrival times predicted by the IASP91 model. Black circles represent the turning depths of the first arrivals of waveforms in the left for velocity model IASP91.

the best-fit model (Figure 10d). It is clear that IASP91 synthetics do not fit the data while the new model predicts correctly the close separation between the EF and CD/DE branches.

The $A B$ and $C D$ branches of the next two seismograms at the distances of $22^{\circ}$ and $18^{\circ}$ sample above and beneath the 410 discontinuity, respectively (Figure $10 \mathrm{~b}$ ). Their separations from the EF branches are matched by the IASP91 predictions, yielding no velocity perturbation at this depth range (Figure 10a). The remaining two $P$ waveforms at closer distance range, however, have the AB branch 5.0 s earlier than the IASP91 predictions, when the $C D$ branch is used as the reference. This corresponds to a high-velocity anomaly of about 5\% at depths $70-230 \mathrm{~km}$ beneath the Lhasa Terrane, similar to those beneath India and the Himalayas (Figure 10b).

\subsubsection{The Qiangtang Terrane}

Because of its location and earthquake-station distribution (Figure 1), the Qiangtang Terrane has the best path coverage. The Terrane's CD-EF separation at distances larger than $23^{\circ}$ is smaller than the prediction of IASP91 (Figure 11a and 11c). Modeling waveforms at these distances therefore also resulted in high-velocity anomaly in the transition zone, similar to beneath the Lhasa Terrane. Because the CD-EF separation between $20^{\circ}$ and $23^{\circ}$ agrees 

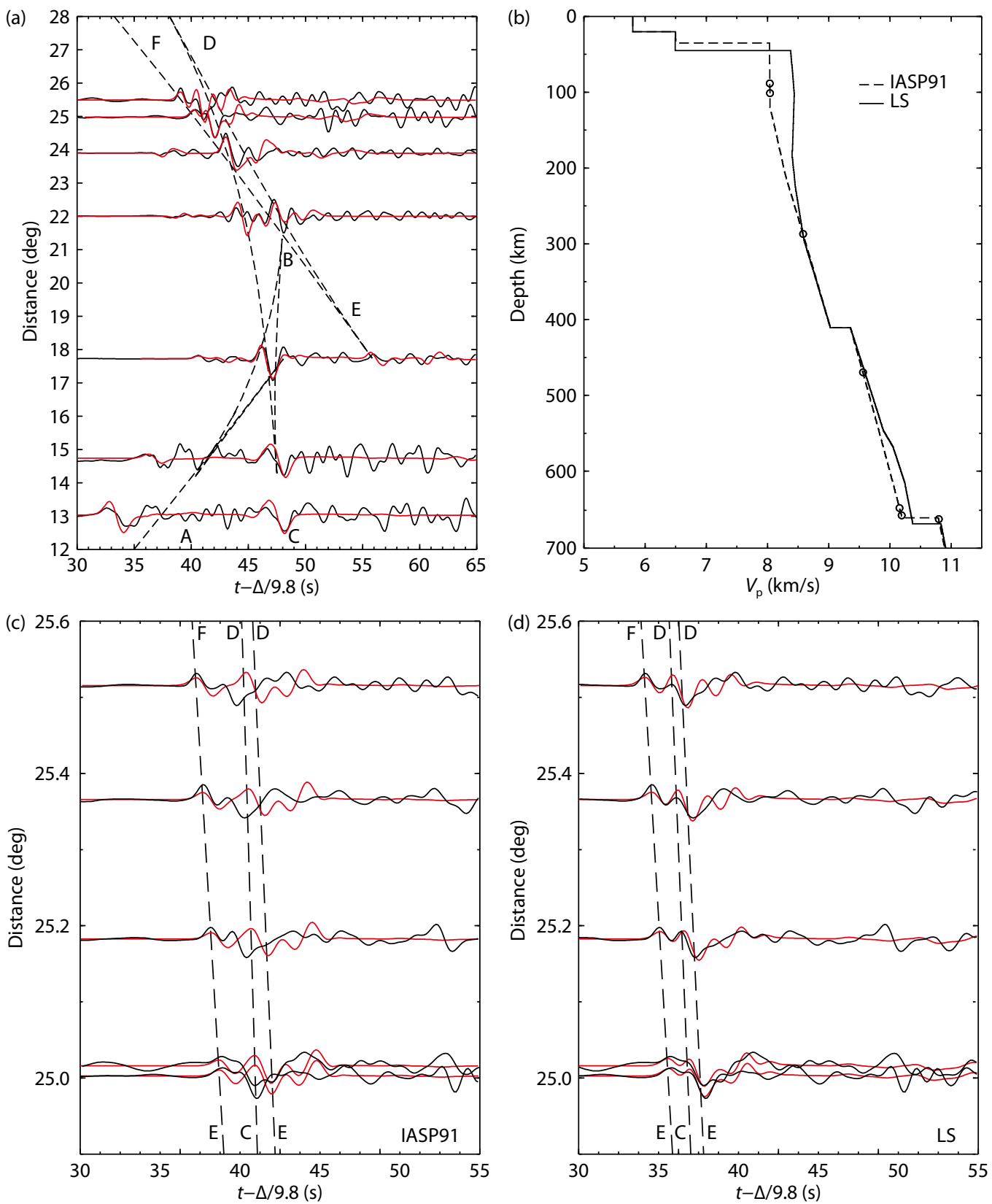

Figure 10. Waveform fits for the Lhasa Terrane (a). Black-colored seismograms are observed data from several earthquakes. Red traces are synthetic seismograms of the best 1-D model shown on the right. Black dashed lines represent arrival times predicted by the IASP91 model. The two panels on the bottom show $\mathrm{P}$ waveforms from an earthquake from the Bay of Bengal (Figure 7) and arrival times (dashed lines) and synthetics (red traces) predicted by the IASP91 model (left) and the final velocity model (right).

with the IASP91 prediction, we constrained the high-velocity anomaly to the bottom half of the transition zone.

The 410 triplication location is further than the IASP91 prediction and the $B$-cusp of the $A B$ and $B C$ branches extends to $25^{\circ}$ as opposed to $21^{\circ}$ predicted by IASP91 (Figures 11a and 11c). The broader BC branch requires a larger velocity jump across the 410 discontinuity. Since the velocity value below the 410 discontinuity has been fitted by modeling of the $C D$ branch in waveforms between $20^{\circ}$ and $23^{\circ}$, we had to reduce the velocity above the 410 discontinuity by about $2.0 \%$. This velocity reduction will significantly delay arrival times of $A B$ branches at larger distances $\left(20^{\circ}\right.$ and $26^{\circ}$ ). The observed data, however, do not show this velocity reduction (Figure 11a). Therefore, we move the 410 discontinuity $20 \mathrm{~km}$ shallower, to $390 \mathrm{~km}$ (Figure $11 \mathrm{~b}$ ). Using the $C D$ branch as the reference phase, the $A B$ branch is about $3.0 \mathrm{~s}$ earlier than the IASP91 predictions. This requires a high-velocity layer in the upper mantle down to $270 \mathrm{~km}$ beneath the Qiangtang Terrane. The magnitude of the velocity perturbation, however, is smaller than those beneath India, the Himalayas, and the Lhasa Terrane. Between $13^{\circ}$ and $18^{\circ}$, the $A B$ branch has an extra set of arrivals, as indicated by the green lines (Figures. 11a). A small discontinuity of $2.5 \%$ velocity jump at the depth of $270 \mathrm{~km}$ is needed to explain this minor triplication of the $A B$ branch. 

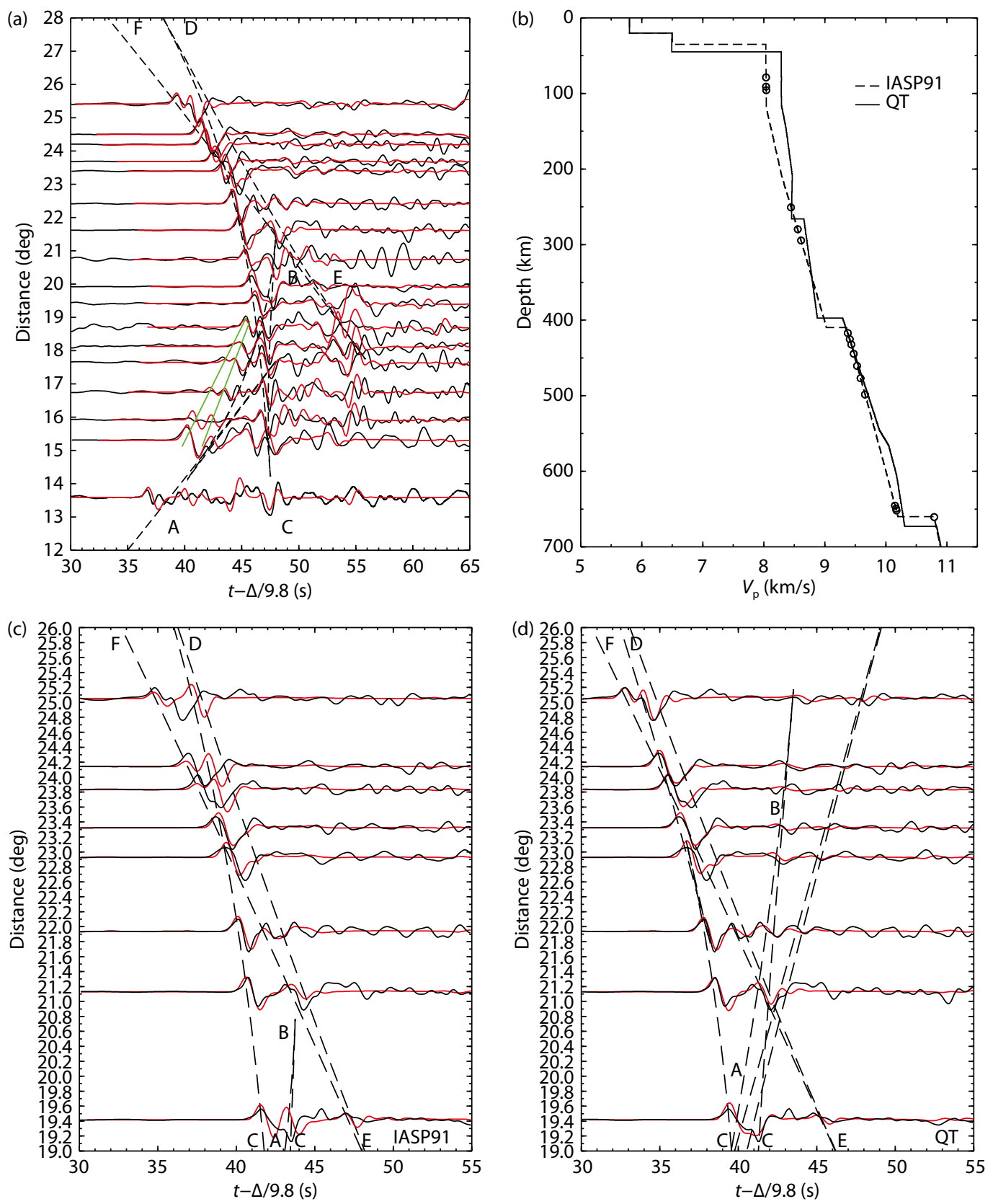

Figure 11. Waveform fits for the Qiangtang Terrane. (c) and (d) show $P$ waveforms from a $65 \mathrm{~km}$ deep Hindu-Burma earthquake and arrival times (dashed lines) and synthetics (red traces) predicted by the IASP91 model (c) and the final velocity model Terrane (d). See Figure 10 for more details. Green lines delineate an extra triplication.

\subsubsection{The Songpan-Garzê Terrane}

The separation of $C D$ and EF branches agrees with that of the IASP91 for waveforms at distances larger than $19^{\circ}$ (Figure 12a), which suggests that the transition-zone velocity structure beneath the Songpan-Garzê Terrane fits the IASP91 model. No transition zone high-velocity anomaly was detected. The SongpanGarzê Terrane has a 410 discontinuity velocity structure similar to that of the Qiangtang Terrane, with a shallow 410 and a reduced velocity above it. This is also due to a broader $B C$ branch in the observed waveforms and early $A B$ branch in the distance range of $20^{\circ}$ to $22^{\circ}$ shown in Figures $12 \mathrm{c}$ and $12 \mathrm{~d}$ for a $21.0 \mathrm{~km}$ deep earthquake in the Hindu-Burma region.

For waveforms between $12^{\circ}$ and $17^{\circ}$, arrivals of the $A B$ branch are about $2.0 \mathrm{~s}$ earlier than the IASP91 predictions. These early arrivals suggest a high-velocity layer in the uppermost mantle, similar to that beneath the Qiangtang Terrane. In order to fit the relatively later $A B$ arrival near $13^{\circ}$, a low-velocity layer between depths of 100 to $180 \mathrm{~km}$ is needed (Figure $12 \mathrm{~b}$ ).

\subsubsection{Tarim Basin}

The Tarim Basin upper-mantle velocity structure was obtained by modeling 10 waveforms with turning points beneath the region (Figure 7). The waveform fits of large distances beyond $19^{\circ}$ indicate that the transition-zone velocity structure is the same as the global average model. However, the AB branch is about $1.5 \mathrm{~s}$ earlier than predicted by the IASP91 model. This requires a high-velo- 

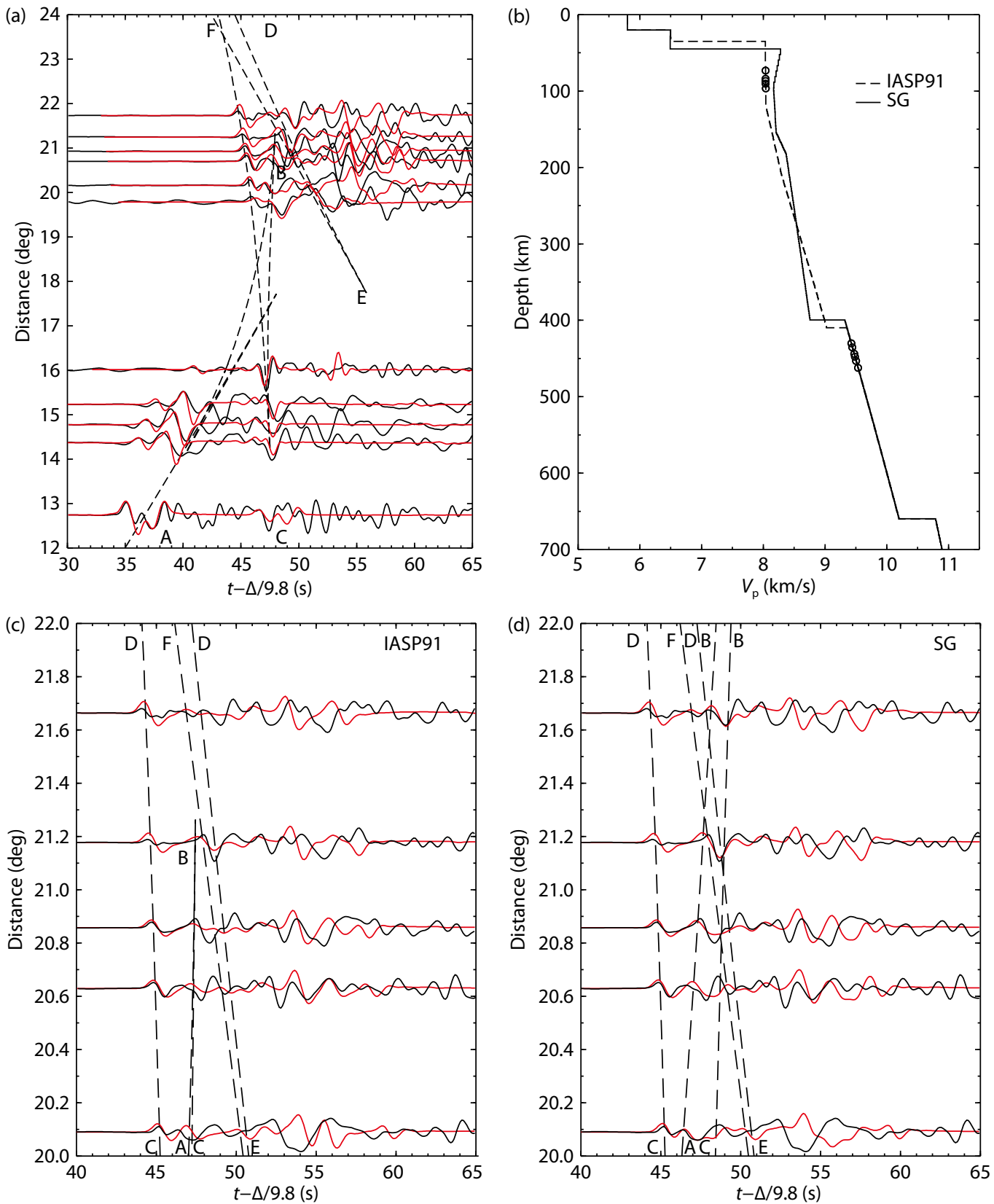

Figure 12. Waveform fits for the Songpan-Garzê Terrane. (c) and (d)show P waveforms from a $21 \mathrm{~km}$ deep Hindu-Burma earthquake and arrival times (dashed lines) and synthetics (red traces) predicted by the IASP91 model (c) and the final velocity model (d). See Figure 10 for more details.

city lid about $150 \mathrm{~km}$ thick in the top of the upper mantle, with a Pn velocity of $8.22 \mathrm{~km} / \mathrm{s}$ (Figure 13). This high-velocity layer is similar to those beneath the Qiangtang Terrane and Songpan-Garzê Terrane.

\section{Discussion}

In this study, waveforms in the upper-mantle distances were fitted using a band-pass filter between $0.02 \mathrm{~Hz}$ and $1.0 \mathrm{~Hz}$; the main frequency content is about $0.5 \mathrm{~Hz}$. Thus, the wavelength of the signals is about $20 \mathrm{~km}$. Using the quarter-wavelength rule, we estimated that the waveform data had a vertical resolution power of less than $5 \mathrm{~km}$.

The horizontal resolution of our results depended on station and earthquake distributions. In regions such as the Lhasa and Qiangtang Terranes, which were sampled by abundant seismic rays, waveforms of turning points separated by less than $4^{\circ}$ were grouped together for modeling. The corresponding horizontal resolution was $400-500 \mathrm{~km}$. In other regions like India and the Tarim Basin where data were scarce, the whole tectonic block was treated as one unit.

Uncertainties of the velocity models come from several sources, including failure to consider lateral velocity structural variations in the crust, earthquake epicenter mis-locations, and earthquake depth errors. Although all the focal depths of the earthquakes used were determined using the differential travel times between the direct $P$ and the depth phases at teleseismic distances, a depth uncertainty of 2-3 km exists since a 1-D velocity model was 

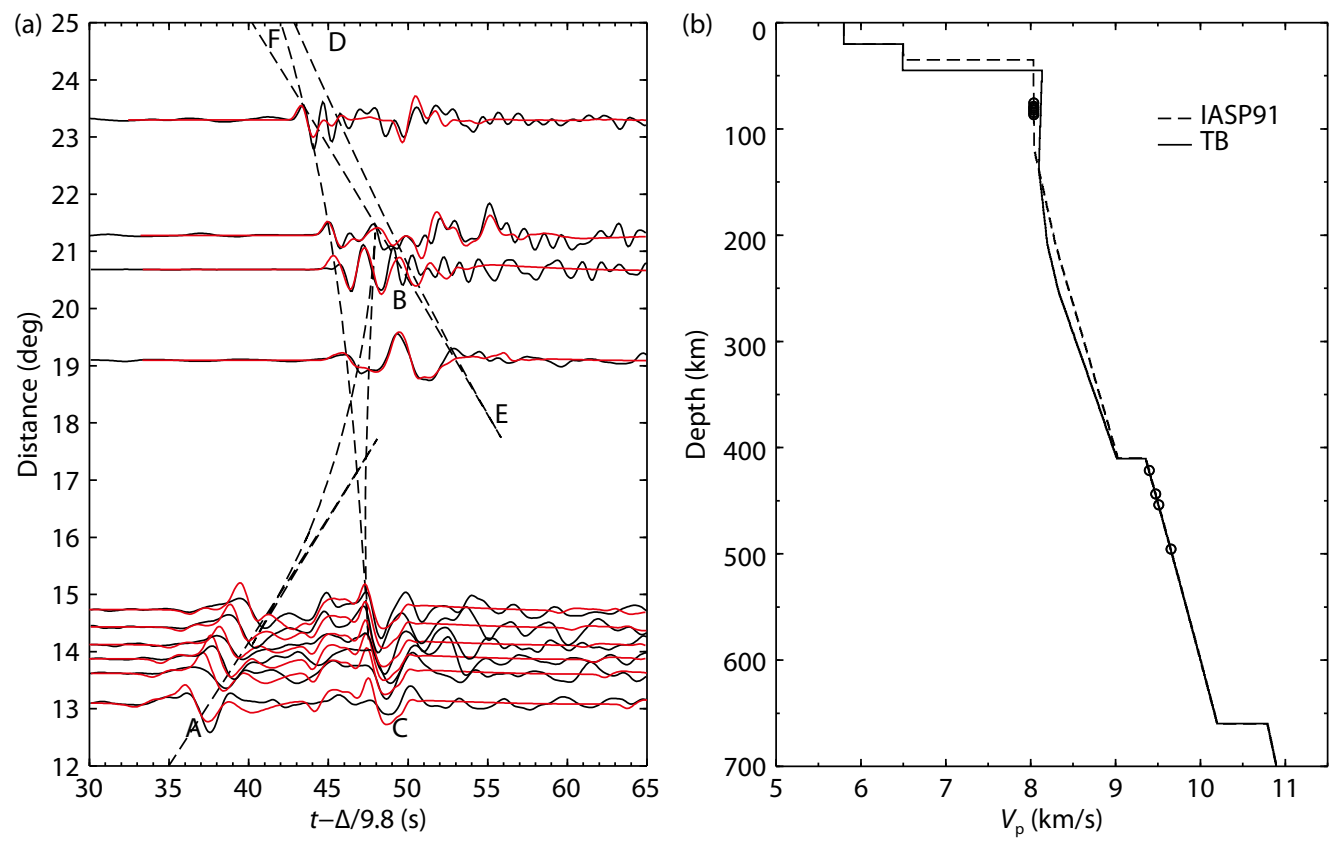

Figure 13. Waveform fits for the Tarim Basin. See Figure 9 for more details.

used. To estimate the effect of source depth uncertainties on the modeling results, we calculated travel-time triplications from a 10$\mathrm{km}$-deep earthquake and a $15-\mathrm{km}$-deep earthquake. After removing the arrival-time delay due to different source depths, the two triplications are almost identical. This indicates that a difference of $5 \mathrm{~km}$ in event depth causes less than $0.1 \mathrm{~s}$ in differential arrival times. Such a small error can be safely ignored.

The waveform modeling results show that a high-velocity lid exists beneath India, the Himalayas, and the Lhasa Terrane. The lid velocity beneath the Tarim Basin is relatively slower than these Terranes, but still faster than those beneath the Qiangtang and the Songpan-Garzê Terranes. Both India and Tarim are Archean cratons and are believed to lie over a cold and strong mantle lithosphere. Travel-time tomography studies suggested a high-velocity anomaly down to $250-300 \mathrm{~km}$ beneath India (Huang $\mathrm{JL}$ and Zhao DP, 2006; Li C et al., 2008; Zhang $\mathrm{H}$ et al., 2012). A thick highvelocity upper mantle lid has also been suggested by Lyon-Caen (1986) using $\mathrm{SH}$-wave triplication between $10^{\circ}$ and $30^{\circ}$. Pn traveltime studies have shown that the Pn velocity beneath India is 8.40 $\mathrm{km} / \mathrm{s}$ (Hearn et al., 2019). Lebedev and Van Der Hilst (2008) obtained a global S-wave velocity model by modeling surface and Swave seismograms. In their model, high-velocity features dominates the upper mantle beneath the Tibetan Plateau. At the $200 \mathrm{~km}$ depth, high-velocity anomalies as large as $5 \%$ could be seen in the Himalayas and the Lhasa Terrane.

Existing descriptions of the upper-mantle velocity structure beneath the Tarim Basin are controversial. Surface-wave dispersion and some travel-time tomographic results have indicated that upper-mantle velocities beneath the Tarim Basin are slow ( $\mathrm{Li} \mathrm{C}$ et al., 2008; Lebedev and Van Der Hilst, 2008), while other travel-time tomography studies have suggested high velocities (Liu M et al., 2004). Yao HJ et al. (2005) used inter-station Rayleigh-wave dispersions and found lateral velocity variations beneath the basin. The northeastern Tarim had higher upper-mantle velocities than the southwestern Tarim. Our waveform modeling did not reveal such a lateral variation. The $8.22 \mathrm{~km} / \mathrm{s} P$ velocity at the top of the mantle agrees with the $\mathrm{Pn}$ velocity from the travel-time tomographic result (Liang CT and Song XD, 2006).

The upper-mantle velocities above $200 \mathrm{~km}$ beneath the Qiangtang and Songpan-Garzê Terranes are lower than in its north and south, especially beneath the Songpan-Garzê Terrane where a low-velocity zone exists (Figure 14). These results agree with previous $\mathrm{Sn}$ and $\mathrm{Pn}$ studies that showed a region of inefficient $\mathrm{Sn}$ propagation and low Pn velocities in northern-central Tibet (Lü $Y$ et al., 2011). Cenozoic volcanism has also been discovered in this region (Gansser, 1980).

Since the upper-mantle velocity structures beneath the Himalayas and the Lhasa Terrane are similar to those beneath India, we suggest that the Indian mantle lithosphere has thrusted beneath the Tibetan Plateau as far as to the Bangong-Nujiang Suture. Based on these results, an upper-mantle structural cross-section along a N-S profile across the Tibetan Plateau can be sketched (Figure 15). Prior to the collision between India and Eurasia about $50 \mathrm{Ma}$ ago, the Eurasian crust had been shortened from $2000 \mathrm{~km}$ to $1000 \mathrm{~km}$, implying a stretching factor of $50 \%$. The uppermantle portion did not change because the collision involved oceanic plates whose upper mantle was hot. With the marching of India northward, the Eurasian upper mantle underwent compression between two continents. Its length changed from $1000 \mathrm{~km}$ to $650 \mathrm{~km}$, a stretching factor of $65 \%$. In short, the $1000 \mathrm{~km} \mathrm{~N}-\mathrm{S}$ convergence between India and Eurasia is accommodated by horizontal shortening of the Eurasian crust and mantle lithosphere with stretching factors of $50 \%$ and $65 \%$, respectively (Figure 15).

The high velocity anomalies in the transition zone beneath the Lhasa and Qiangtang Terranes are interpreted as the remnants of the delamination of the Eurasian mantle lithosphere at about 15 Ma ago, as suggested by Chen WP and Tseng (2007). This rem- 

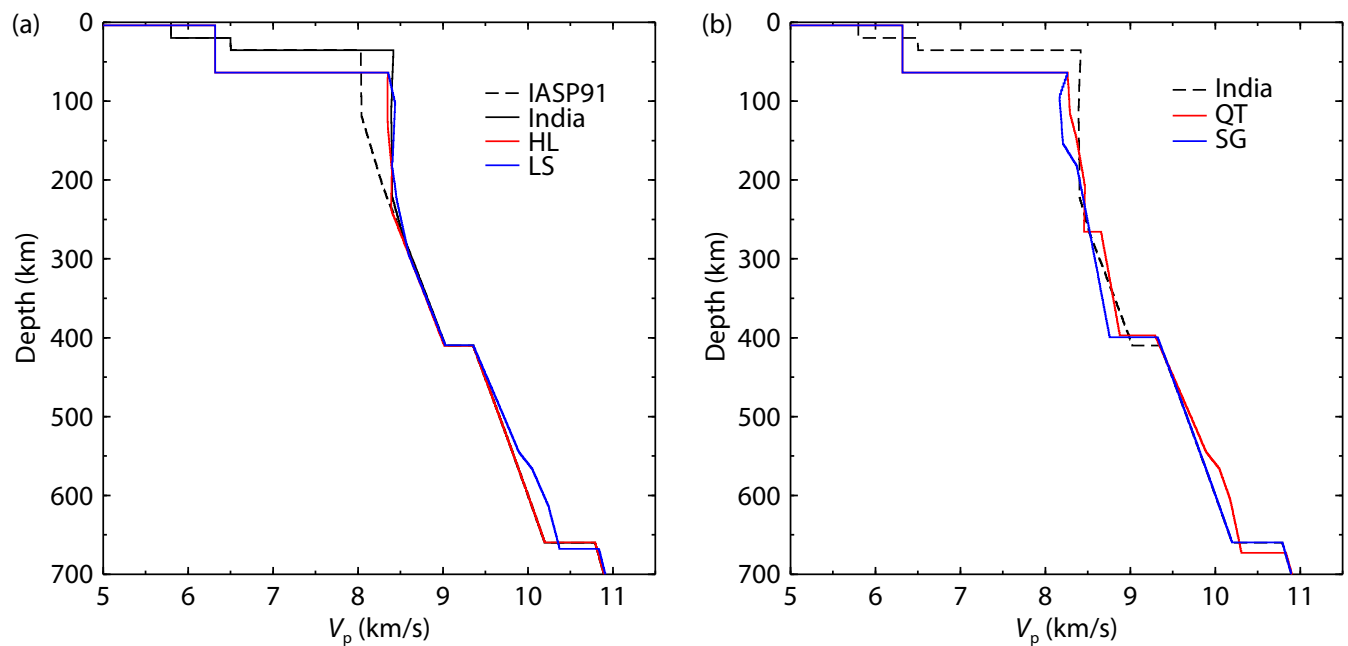

Figure 14. Left panel compares upper-mantle velocity models in India, the Himalayas (HL), and the Lhasa Terrane (LS). Right panel shows comparison of velocity models in the Qiangtang Terrane (QT) and the Songpan-Garzê Terrane (SG) with the model of India.

(a)

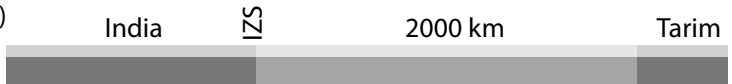

(b)
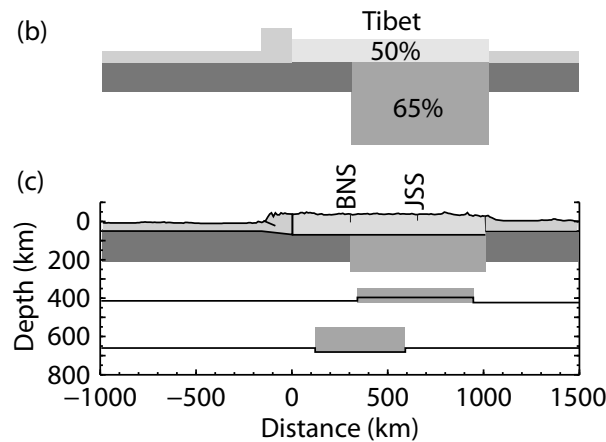

Figure 15. N-S cross-sections show crustal and upper-mantle structure beneath India and the Tibetan Plateau before the collision (a) and after collision with $1000 \mathrm{~km}$ horizontal shortening (b). The Indian mantle lithosphere underthrusts beneath Tibet up to the Bangong-Nujiang Suture. The upper-mantle structures derived from waveform modeling are shown in (c). All distances are with respect to the IZS.

nant can be seen for a distance of about $450 \mathrm{~km}$ beneath the northern Lhasa Terrane and the whole of the Qiangtang Terrane (Figure 15). The low velocities between the depths of 100 and 200 km under the Qiangtang and Songpan-Garzê Terranes are caused by delamination in a more recent time of a portion of the thickened Eurasian lithosphere. This delaminated lithosphere, about $650 \mathrm{~km}$ long, is now resting on top of the 410 discontinuity and produces the observed velocity jump at the depth of $270 \mathrm{~km}$ beneath the Qiangtang and the Songpan-Garzê Terranes. It lowers the temperatures of the 410 discontinuity and causes the discontinuity to be elevated by about $20 \mathrm{~km}$. Receiver function images also suggest a thickened transition-zone structure about 15-20 km beneath the Lhasa and Qiangtang Terranes (e. g. Duan YH et al., 2017).

\section{Conclusions}

By fitting $\mathrm{P}$ waveforms in the distance range between $12^{\circ}$ and $30^{\circ}$, we obtained upper-mantle velocity models beneath six regions along a N-S profile across the Tibetan Plateau. The results show that the upper-mantle velocity structures beneath India, the Himalayas, and the Lhasa Terrane are similar and contain a high-velocity lid about $250 \mathrm{~km}$ thick. The Tarim Basin also lies above a highvelocity upper-mantle lid. The upper-mantle velocities deeper than $200 \mathrm{~km}$ beneath the Qiangtang and Songpan-Garzê Terranes are lower than those in the north and south, especially those beneath the Songpan-Garzê Terrane. A high-velocity anomaly can be seen beneath these two terranes between $270 \mathrm{~km}$ and $410 \mathrm{~km}$, and the 410 discontinuity is elevated by $20 \mathrm{~km}$. We also found high-velocity anomalies in the transition zone below 500 $\mathrm{km}$ under the Lhasa and Qiangtang Terranes. The results suggest that the Tibetan Plateau was generated by the thrusting of the Indian mantle lithosphere under the southern part of Tibet. The India-Eurasian convergence is a two-phase process. Two portions of the thickened Eurasian lithosphere were delaminated in southern and northern Tibet. They are now sitting atop the 660 and 410 discontinuities, respectively.

\section{Acknowledgments}

We thank the editor, Dr. Wei Leng, for handling the manuscript and two anonymous reviewers for their constructive suggestions that substantially improve the paper. The Chinese National Digital Seismic Network and IRIS provided data used in this study. This work is supported by funding from the Strategic Priority Research Program (B) of Chinese Academy of Sciences through grant XDB18010304 and Natural Science Foundation of China through grant 41322027, 41374060, 41374079, 41661164035.

\section{References}

Alsdorf, D., Makovsky, Y., Zhao, W., Brown, L. D., Nelson, K. D., Klemperer, S., Hauck, M., Ross, A., Cogan, M., ... Kuo, J. (1998). INDEPTH (International Deep Profiling of Tibet and the Himalaya) multichannel seismic reflection data: description and availability. J. Geophys. Res., 103(B11), 26993-26999. https://doi.org/10.1029/98JB01078 
Argand, E. (1924). La tectonique de I'Asie. In Proceedings of the 13th International Geological Congress (pp. 171-372). Brussels.

Bao, X. W., Song, X. D., Xu, M. J., Wang, L. S., Sun, X. X., Mi, N., Yu, D. Y., and Li, H. (2013). Crust and upper mantle structure of the North China Craton and the NE Tibetan Plateau and its tectonic implications. Earth Planet. Sci. Lett., 369370, 129-137. https://doi.org/10.1016/j.epsl.2013.03.015

Bina, C. R. (1991). Mantle discontinuities. Rev. Geophys, 29(S2), 783-793. https://doi.org/10.1002/rog.1991.29.s2.783

Chen, W. P., and Tseng, T. L. (2007). Small 660-km seismic discontinuity beneath Tibet implies resting ground for detached lithosphere. J. Geophys. Res., 112(B5), B05309. https://doi.org/10.1029/2006JB004607

Chu, R. S., Zhu, L. P., and Helmberger, D. V. (2009). Determination of earthquake focal depths and source time functions in central Asia using teleseismic $P$ waveforms. Geophys. Res. Lett., 36(17), L17317. https://doi.org/10.1029/2009GL039494

Chu, R. S., Schmandt, B., and Helmberger, D. V. (2012a). Juan de Fuca subduction zone from a mixture of tomography and waveform modeling. J. Geophys. Res., 117(B3), B03304. https://doi.org/10.1029/2012JB009146

Chu, R. S., Schmandt, B., and Helmberger, D. V. (2012b). Upper mantle $P$ velocity structure beneath the Midwestern United States derived from triplicated waveforms. Geochem. Geophys. Geosyst., 13(2), Q0AK04.

https://doi.org/10.1029/2011GC003818

Chu, R. S., Leng, W., Helmberger, D. V., and Gurnis, M. (2013). Hidden hotspot track beneath the eastern United States. Nat. Geosci., 6(11), 963-966. https://doi.org/10.1038/ngeo1949

Chu, R. S., Helmberger, D., and Gurnis, D. (2014). Upper mantle surprises derived from the recent Virginia earthquake waveform data. Earth Planet. Sci. Lett., 402, 167-175. https://doi.org/10.1016/j.epsl.2012.10.023

Chu, R. S., and Helmberger, D. (2014). Lithospheric waveguide beneath the Midwestern United States; massive low-velocity zone in the lower crust. Geochem. Geophys. Geosyst., 15(4), 1348-1362.

https://doi.org/10.1002/2013GC004914

De La Torre, T. L., and Sheehan, A. (2005). Broadband seismic noise analysis of the Himalayan Nepal Tibet seismic experiment. Bull. Seismol. Soc. Am., 95(3), 1202-1208. https://doi.org/10.1785/0120040098

Duan, Y. H., Tian, X. B., Liang, X. F., Li, W., Wu, C. L., Zhou, B. B., and lqbal, J. (2017). Subduction of the Indian slab into the mantle transition zone revealed by receiver functions. Tectonophysics, 702, 61-69. https://doi.org/10.1016/j.tecto.2017.02.025

England, P., and Houseman, G. (1986). Finite strain calculations of continental deformation: 2. Comparison with the India-Asia collision zone. J. Geophys. Res., 91(B3), 3664-3676. https://doi.org/10.1029/JB091iB03p03664

Fan, G. W., and Wallace, T. (1991). The determination of source parameters for small earthquakes from a single, very broadband seismic station. Geophys. Res. Lett., 18(8), 1385-1388. https://doi.org/10.1029/91GL01804

Gansser, A. (1980). The significance of the Himalayan suture zone. Tectonophysics, 62(1-2), 37-40, 43-52. https://doi.org/10.1016/00401951(80)90134-1

Guo, X. Y., Gao, R., Randy Keller, G., Xu, X., Wang, H. Y., and Li, W. H. (2013). Imaging the crustal structure beneath the eastern Tibetan Plateau and implications for the uplift of the Longmen Shan range. Earth Planet. Sci. Lett., 379, 72-80. https://doi.org/10.1016/j.epsl.2013.08.005

He, R. Z., Zhao, D. P., Gao, R., and Zheng, H. W. (2010). Tracing the Indian lithospheric mantle beneath central Tibetan Plateau using teleseismic tomography. Tectonophysics, 491(1-4), 230-243.

https://doi.org/10.1016/j.tecto.2010.03.015

Hearn, T. M., Ni, J. F., Wang, H. Y., Sandvol, E. A., and Chen, Y J. (2019). Depthdependent $P_{n}$ velocities and configuration of Indian and Asian lithosphere beneath the Tibetan Plateau. Geophys. J. Int., 217(1), 179-189. https://doi.org/10.1093/gji/ggz013

Huang, J. L., and Zhao, D. P. (2006). High-resolution mantle tomography of China and surrounding regions. J. Geophys. Res., 111(B9), B09305. https://doi.org/10.1029/2005JB004066

Johnson, M. R. W. (2002). Shortening budgets and the role of continental subduction during the India-Asia collision. Earth-Sci. Rev., 59(1-4), 101-123. https://doi.org/10.1016/S0012-8252(02)00071-5
Kao, H., Gao, R., Rau, R. J., Shi, D. N., Chen, R. Y., Guan, Y., and Wu, F. T. (2001). Seismic image of the Tarim Basin and its collision with Tibet. Geology, 29(7), 575-578. https://doi.org/10.1130/00917613(2001)029<0575:SIOTTB>2.0.CO;2

Lebedev, S., and Van Der Hilst, R. D. (2008). Global upper-mantle tomography with the automated multimode inversion of surface and $S$-wave forms. Geophys. J. Int., 173(2), 505-518. https://doi.org/10.1111/j.1365246X.2008.03721.X

Li, C., Van der Hilst, R. D., Meltzer, A. S., and Engdahl, E. R. (2008). Subduction of the Indian lithosphere beneath the Tibetan Plateau and Burma. Earth Planet. Sci. Lett., 274(1-2), 157-168. https://doi.org/10.1016/j.epsl.2008.07.016

Li, H. Y., Shen, Y., Huang, Z. X., Li, X. F., Gong, M., Shi, D. N., Sandvol, E., and Li, A. B. (2014). The distribution of the mid-to-lower crustal low-velocity zone beneath the northeastern Tibetan Plateau revealed from ambient noise tomography. J. Geophys. Res., 119(3), 1954-1970. https://doi.org/10.1002/2013JB010374

Liang, C. T., and Song, X. D. (2006). A low velocity belt beneath northern and eastern Tibetan Plateau from Pn tomography. Geophys. Res. Lett., 33(22), L22306. https://doi.org/10.1029/2006GL027926

Liang, X. F., Chen, Y., Tian, X. B., Chen, Y. J., Ni, J., Gallegos, A., Klemperer, S. L., Wang, M. L., Xu, T., ... Teng, J. W. (2016). 3D imaging of subducting and fragmenting Indian continental lithosphere beneath southern and central Tibet using body-wave finite-frequency tomography. Earth Planet. Sci. Lett., 443, 162-175. https://doi.org/10.1016/j.epsl.2016.03.029

Liu, M., Cui, X. J., and Liu, F. T. (2004). Cenozoic rifting and volcanism in eastern China: a mantle dynamic link to the Indo-Asian collision?. Tectonophysics, 393(3-4), 29-42. https://doi.org/10.1016/j.tecto.2004.07.029

Liu, Q. Y., Van Der Hilst, R. D., Li, Y., Yao, H. J., Chen, J. H., Guo, B., Qi S. H., Wang, J., Huang, H., and Li, S. C. (2014). Eastward expansion of the Tibetan Plateau by crustal flow and strain partitioning across faults. Nat. Geosci., 7(5), 361-365. https://doi.org/10.1038/ngeo2130

Lü, Y., Ni, S. D., Liu, B., and Sun, Y. S. (2011). $P_{\mathrm{n}}$ tomographic velocity and anisotropy beneath the Tibetan Plateau and the adjacent regions. Earth, Planets Space, 63(11), 1169-1173. https://doi.org/10.5047/eps.2011.07.013

Lyon-Caen, H. (1986). Comparison of the upper mantle shear wave velocity structure of the Indian Shield and the Tibetan Plateau and Tectonic Implications. Geophys. J. Int., 86(3), 727-749. https://doi.org/10.1111/j.1365246X.1986.tb00657.x

Meltzer, A, Sarker, G., Beaudoin, B., Seeber, L., and Armbruster, J. G. (2001). Seismic characterization of an active metamorphic massif, Nanga Parbat, Pakistan Himalaya. Geology, 29(7), 651-654. https://doi.org/10.1130/00917613(2001)029<0651:SCOAAM>2.0.CO;2

Molnar, P., and Tapponnier, P. (1975). Cenozoic tectonics of Asia: effects of a continental collision. Science, 189(4201), 419-426.

https://doi.org/10.1126/science.189.4201.419

Nelson, K. D., Zhao, W. J., Brown, L. D., Kuo, J., Che, J. K., Liu, X. W., Klemperer, S. L., Makovsky, Y., Meissner, R., ... Edwards, M. (1996). Partially molten middle crust beneath southern Tibet: synthesis of Project INDEPTH results. Science, 274(5293), 1684-1688. https://doi.org/10.1126/science.274.5293.1684

Owens, T. J., Randall, G. E., Wu, F. T., and Zeng, R. S. (1993). Passcal instrument performance during the Tibetan Plateau passive seismic experiment. Bull. Seismol. Soc. Am., 83(6), 1959-1970.

Owens, T. J., and Zandt, G. (1997). Implications of crustal property variations for models of Tibetan Plateau evolution. Nature, 387(6628), 37-43. https://doi.org/10.1038/387037a0

Pan, S. Z., and Niu, F. L. (2011). Large contrasts in crustal structure and composition between the Ordos Plateau and the NE Tibetan Plateau from receiver function analysis. Earth Planet. Sci. Lett., 303(3-4), 291-298. https://doi.org/10.1016/j.epsl.2011.01.007

Royden, L. H., Burchfiel, B. C., and Van Der Hilst, R. D. (2008). The geological evolution of the Tibetan Plateau. Science, 321(5892), 1054-1058. https://doi.org/10.1126/science.1155371

Shen, X. Z., Zhou, Y. Z., Zhang, Y. S., Mei, X. P., Guo, X., Liu, X. Z, Qin, M. Z., Wei, C. $X$. , and Li, C. Q. (2014). Receiver function structures beneath the deep large faults in the northeastern margin of the Tibetan Plateau. Tectonophysics, 610, 63-73. https://doi.org/10.1016/j.tecto.2013.10.011 
Sol, S., Meltzer, A., Bürgmann, R., Van Der Hilst, R. D., King, R., Chen, Z., Koons, P. O., Lev, E., Liu, Y. P., ... Zurek, B. (2007). Geodynamics of the southeastern Tibetan Plateau from seismic anisotropy and geodesy. Geology, 35(6), 563-566. https://doi.org/10.1130/G23408A.1

Tapponnier, P., Xu, Z. Q., Roger, F., Meyer, B., Arnaud, N., Wittlinger, G., and Yang, J. S. (2001). Oblique stepwise rise and growth of the Tibet Plateau. Science, 294(5547), 1671-1677. https://doi.org/10.1126/science.105978

Velasco, A. A., Gee, V. L., Rowe, C., Grujic, D., Hollister, L. S., Hernandez, D., Miller, K. C., Tobgay, T., Fort, M., Harder, S. (2007). Using small, temporary seismic networks for investigating tectonic deformation: brittle deformation and evidence for strike-slip faulting in Bhutan. Seismol. Res. Lett., 78(4), 446-453. https://doi.org/10.1785/gssrl.78.4.446

Wang, C. Y., Lou, H., Silver, P. G., Zhu, L. P., and Chang, L. J. (2010). Crustal structure variation along $30^{\circ} \mathrm{N}$ in the eastern Tibetan Plateau and its tectonic implications. Earth Planet. Sci. Lett., 289(3-4), 367-376. https://doi.org/10.1016/j.epsl.2009.11.026

Xu, Q., Zhao, J. M., Yuan, X. H., Liu, H. B., and Pei, S. P. (2015). Mapping crustal structure beneath southern Tibet: seismic evidence for continental crustal underthrusting. Gondwana Res., 27(4), 1487-1493. https://doi.org/10.1016/j.gr.2014.01.006

$\mathrm{Xu}, \mathrm{Y} ., \mathrm{Li}, \mathrm{Z}$. W., and Roecker, S. W. (2007). Uppermost mantle structure and its relation with seismic activity in the central Tien Shan. Geophys. Res. Lett., 34(10), L10304. https://doi.org/10.1029/2007GL029708

Yang, Y. J., Zheng, Y., Chen, S. Y., Zhou, S. Y., Celyan, S., Sandvol, E., Tilmann, F., Priestley, K., Hearn, T. M., ... Ritzwoller, M. H. (2010). Rayleigh wave phase velocity maps of Tibet and the surrounding regions from ambient seismic noise tomography. Geochem. Geophys. Geosyst., 11(8), Q08010. https://doi.org/10.1029/2010GC003119

Yao, H. J., Xu, G. M., Zhu, L. B., and Xiao, X. (2005). Mantle structure from interstation Rayleigh wave dispersion and its tectonic implication in western China and neighboring regions. Phys. Earth Planet. Inter., 148(1), 39-54. https://doi.org/10.1016/j.pepi.2004.08.006

Yao, H. J., Van Der Hilst, R. D., and De Hoop, M. V. (2006). Surface-wave array tomography in SE Tibet from ambient seismic noise and two-station analysis - I. Phase velocity maps. Geophys. J. Int., 166(2), 732-744. https://doi.org/10.1111/j.1365-246X.2006.03028.x

Yin, A., and Harrison, T. M. (2000). Geologic evolution of the Himalayan-Tibetan orogen. Annu. Rev. Earth Planet. Sci., 28, 211-280.

https://doi.org/10.1146/annurev.earth.28.1.211

Yue, H., Chen, Y. J., Sandvol, E., Ni, J., Hearn, T., Zhou, S. Y., Feng, Y. G., Ge, Z. X., Trujillo, A., ... Liu, Z. (2012). Lithospheric and upper mantle structure of the northeastern Tibetan Plateau. J. Geophys. Res., 117(B5), B05307. https://doi.org/10.1029/2011JB008545

Zhang, H., Zhao, D. P., Zhao, J. M., and Xu, Q. (2012). Convergence of the Indian and Eurasian plates under eastern Tibet revealed by seismic tomography. Geochem. Geophys. Geosyst., 13(6), Q06W14. https://doi.org/10.1029/2012GC004031

Zhang, R. Q., Wu, Q., Li, Y. H., and Zeng, R. S. (2011). Differential patterns of SH and $\mathrm{P}$ wave velocity structures in the transition zone beneath northwestern Tibet. Sci. China Earth Sci., 54(10), 1551-1562. https://doi.org/10.1007/s11430-011-4228-8

Zhao, J. M., Yuan, X. H., Liu, H. B., Kumar, P., Pei, S. P., Kind, R., Zhang, Z. J., Teng, J. W., Ding, L., ... Wang, W. (2010). The boundary between the Indian and Asian tectonic plates below Tibet. Proc. Natl. Acad. Sci. U.S.A., 107(25), 11229-11233. https://doi.org/10.1073/pnas.1001921107

Zhao, L. S., Helmberger, D. V., and Harkrider, D. G. (1991). Shear-velocity structure of the crust and upper mantle beneath the Tibetan Plateau and southeastern China. Geophys. J. Int., 105(3), 713-730. https://doi.org/10.1111/j.1365-246X.1991.tb00807.x

Zhao, W., Mechie, J., Brown, L. D., Guo, J., Haines, S., Hearn, T., Klemperer, S. L., Ma, Y. S., Meissner, R., ... Saul, J. (2001). Crustal structure of central Tibet as derived from project INDEPTH wide-angle seismic data. Geophys. J. Int., 145(2), 486-498. https://doi.org/10.1046/j.0956-540x.2001.01402.x

Zhao, W. J., Nelson, K. D., and Team, P. I. (1993). Deep seismic reflection evidence for continental underthrusting beneath southern Tibet. Nature, 366(6455), 557-559. https://doi.org/10.1038/366557a0

Zhao, W. L., and Morgan, W. J. (1985). Uplift of Tibetan Plateau. Tectonics, 4(4), 359-369. https://doi.org/10.1029/TC004i004p00359

Zhu, L. P., Owens, T. J., and Randall, G. E. (1995). Lateral variation in crustal structure of the northern Tibetan Plateau inferred from teleseismic receiver functions. Bull. Seismol. Soc. Am., 85(6), 1531-1540.

Zhu, L. P., and Helmberger, D. V. (1998). Moho offset across the northern margin of the Tibetan Plateau. Science, 281(5380), 1170-1172.

https://doi.org/10.1126/science.281.5380.1170 